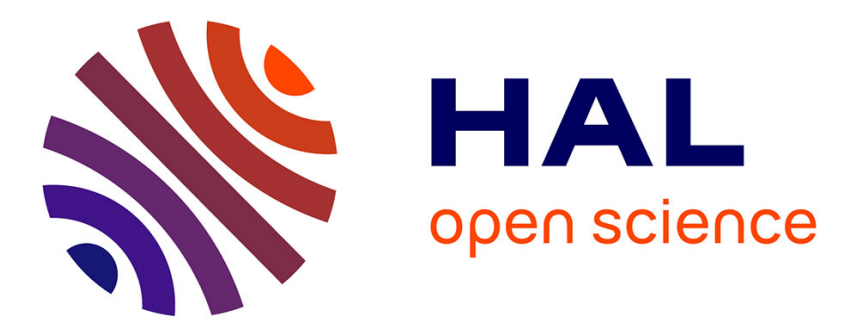

\title{
Chemists around the World, Take Your Part in the Circular Economy! \\ Gregory Chatel
}

\section{To cite this version:}

Gregory Chatel. Chemists around the World, Take Your Part in the Circular Economy!. Chemistry A European Journal, 2020, 26 (44), pp.9665-9673. 10.1002/chem.202002327 . hal-02971324

\section{HAL Id: hal-02971324 \\ https://hal.science/hal-02971324}

Submitted on 8 Mar 2021

HAL is a multi-disciplinary open access archive for the deposit and dissemination of scientific research documents, whether they are published or not. The documents may come from teaching and research institutions in France or abroad, or from public or private research centers.
L'archive ouverte pluridisciplinaire HAL, est destinée au dépôt et à la diffusion de documents scientifiques de niveau recherche, publiés ou non, émanant des établissements d'enseignement et de recherche français ou étrangers, des laboratoires publics ou privés. 


\title{
Chemists around the world, take your part in the circular economy!
}

\author{
Gregory Chatel ${ }^{*[a]}$
}

\begin{abstract}
Based on recent examples and initiatives reported in the literature, this concept article discusses how chemistry can contribute to the circular economy approach in order to improve our current and future economical, societal and environmental system. Through five proposed levels of contribution, chemists can take a significant part in this global approach via the consideration of green chemistry principles, the simplification of syntheses, the limitation of complex products preparation, the efficient utilization of resources but also the novel ways of waste valorization. A more systematic and generalized environmental and economic assessment from the lab-scale is also recommended. At last, chemists have to work even more collaboratively and in a multidisciplinary way, within chemistry and beyond.
\end{abstract}

\section{Introduction}

In March 2020, the European Commission adopted a new Circular Economy Action Plan, as one of the main building blocks of the European Green Deal. ${ }^{[1]}$ In this context, the Executive VicePresident for the European Green Deal, Frans Timmermans, specified that the current economy in Europe is still mostly linear, with only $12 \%$ of secondary materials and resources being brought back into the economy. There is a huge potential to be exploited both for businesses and consumers. Indeed, the European Green Deal sets a roadmap towards a climate-neutral circular economy, where economic growth is decoupled from resource use. Chemists in Europe but also all around the world have a real role to play in establishing a circular economy.

Let's start from the origin and meanings of each word. Circular Economy. "Economy" is borrowed from Latin oeconomia and from Ancient Greek oikovopía which literally means "management of a household". Here, we can consider that we are talking about our home, our Planet, and the management of their resources, our common resources, which are not inexhaustible. "Circular" from Latin circulus, a diminutive of circus meaning "circle", "ring" or even "orbit". It is therefore a matter of managing our house in a circular way, to gauge our consumption of resources, taking into account our production of waste and/or pollution, but also their impacts. Interestingly, Rizos et al. summarized and discussed the different definitions of the circular economy concept given by several authors and organizations. It is often opposed to the linear economy ("make, use, dispose"), highlighting the need to create closed loops of material flows and to reduce the consumption of virgin resources and its attendant harmful environmental impacts. ${ }^{[2]}$

The circular economy is not a constraint, but a real opportunity to innovate by doing it differently. A circular economy increases the value of a material resource by maximizing its conversion into products (high value), and eliminating waste (low value). In addition, the lifetime of products is increased through responsible product design..$^{[3]}$

Circular economy is a concept promoted at both policymakers and business communities, especially in EU and more generally worldwide. Differently from recycling practice, circular

[a] Dr. Gregory Chatel

Univ. Savoie Mont Blanc, LCME, 73000 Chambéry, France.

E-mail: gregory.chatel@univ-smb.fr

Twitter: https://twitter.com/gregory chate economy emphasizes, among other aspects, waste utilization as a way to close the cycle and minimize the use of resources (Figure 1). When a product reaches the end of its function, reuse and recycling provides an opportunity to prolong the usefulness of its constituent parts even further. Meanwhile the inherent value of the material embodied in the product is extended rather than wasted. One of the major challenge of this strategy, for example for waste, is about the need to convert low economic value waste into high value products and by developing a process globally less expensive than the corresponding virgin fossil resource. It is undoubtedly in this kind of strategy that the chemist will be able to contribute to the development of new approaches.

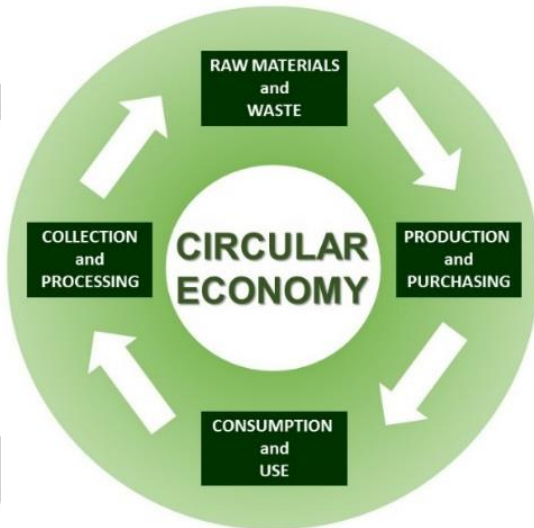

Figure 1. Representative scheme of circular economy.

\section{What could be circular in chemistry?}

Sheldon summarized that the concept of green chemistry (12 principles of green chemistry), proposed by Anastas and Warner at the end of 1990s (Figure 2), ${ }^{[4]}$ is basically based on the prevention of pollution by waste minimization and the avoidance of toxic and hazardous substances in the production and application of chemical products. ${ }^{[5]}$ The atom economy and the Efactor consideration, ${ }^{[6]}$ the role of catalysis avoiding stoichiometric amount of reagents ${ }^{[7]}$ and the use of renewable resources ${ }^{[8]}$ can constitute a first level of contribution of chemistry to a greener economy and promote the limitation of unwanted waste. To accomplish the goals of green design and sustainability in the industry, 12 principles of green engineering were announced by Anastas and Zimmerman, as a set of methodologies to prevent waste, save energy, reduce the environmental impact of the developed processes and promote systems designed for performance in a commercial "afterlife" (Figure 2). ${ }^{[9]}$

\begin{tabular}{|l|l|}
\hline PRINCIPLE OF GREEN CHEMISTRY & PRINCIPLE OF GREEN ENGINEERING \\
P: Prevent waste & I: Inherently non-hazardous and safe \\
R: Renewable materials & M: Minimize material diversity \\
O: Omit derivatization steps & P: Prevention instead of treatment \\
D: Degradable chemical products & R: Renewable material and energy inputs \\
U: Use sage synthetic methods & O: Output-led design \\
C: Catalytic reagents & V: Very simple \\
T: Temperature, pressure ambient & E: Efficient use of mass, energy, space \& time \\
I: In-process monitoring & M: Meet the need \\
V: Very few auxiliary substances & E: Easy to separate by design \\
E: E-factor, maximize feed in product & N: Networks for exchange of local mass \& energy \\
L: Low toxicity of chemical products & T: Test the life cycle of the design \\
Y: Yes it's safe & S: Sustainability throughout product life cycle \\
\hline
\end{tabular}

Figure 2. The condensed twenty-four principles of green chemistry and green engineering. ${ }^{[9 b]}$ 
Regarding the resources used by chemistry (starting substrates or materials, reagents, energy, solvents, energy, etc.), Lin et al. are right to insist that renewability should not be confused with sustainability. ${ }^{[10]}$ Indeed, renewability is relating to a naturel resource (solar energy, water, biomass, etc.) that is never used up or that can be replaced by new growth. Sustainability is a voluntary process that focuses on meeting the needs of the present without compromising the ability of future generations to meet their needs, as defined by United Nations in 1987. [11] Authors illustrated this with the biofuel production example, in which using edible food crops represents an unsustainable option. ${ }^{[10]}$ More generally, even if the starting molecules and materials involved in a chemical reaction or process are renewable and low-cost, it could be not sufficient with respect to the overall sustainability of the reaction, the process and/or the application of the synthesized/manufactured product (e.g., its biodegradability, its recyclability, its potential re-use, its global impact on the environment, etc.). However, renewability and sustainability often intersect and contribute to circular economy in terms of (i) implementation of closed loops of production/transformation, (ii) reduction of the consumption of virgin resources and (iii) limitation of the impacts on Earth and future generation of Humans. Thus, circular economy has broader considerations than respecting the 24 principles of the green chemistry and the green engineering, taking into account sustainability and their economic and social components, in addition to environmental components.

Clark and coworkers discussed the role of chemists in a world without waste. ${ }^{[12]}$ Through chemistry, the circular economy can provide the basis of innovative products, made from renewable feedstocks and designed to be reused, recycled or the feedstock renewed through natural processes. However, chemical complexity often complicates product recycling and manufacturing sustainability.[13] Fifteen principles integrating chemistry into a circular economy were proposed to reduce the molecular complexity to the minimum, design products for recycling, ensure traceability, keep processes as simple as possible or develop circular metrics (Figure 3).

- Keep molecular complexity to the minimum required for the desired
performance, including end-of-life.
- Design products for recycling, including all additives and other
components of the product.
- Reduce and simplify diversity and dynamics of substance, material,
and product flows and adapt innovation speed of products to adaptation
speed of recycling.
- Avoid complex products.
- Minimize use of product components that cannot easily be separated
and recycled.
- Design products not suitable for capture and recycling for complete
fast mineralization at the end of their lives.
- Prevent raw materials from becoming critical through reduced use and
efficient recovery and recycling.
- Avoid entropic losses and transfers.
- Avoid rebound effects.
- Be responsible for/develop ownership of your product throughout its
complete life cycle, including recycling.
- Ensure traceability and consider use of product digital passports.
- Develop and apply circular metrics.
- Change traditional chemical practices based on "bigger-faster" into
"optimal adapted-better-safer" and change ownership to rent, lease, and
share business models.
- Keep processes as simple as possible with a minimum number of
steps, auxiliaries, energy, and unit operations.
- Design processes for optimal material recovery of auxiliaries, unused
substrates, and unintended by-products.

Figure 3. The fifteen recommendations to integrate chemistry into a circular economy proposed by Clark et al. ${ }^{[13]}$

Interestingly, Slootweg et al. recently proposed the term "circular chemistry" and formulated 12 associated principles "for a circular chemistry" (Figure 4).[14] The goal of the authors was to provide a framework analogous to that of green chemistry, adapted to facilitate the transition to a circular economy. In this article, they proposed "to make chemical processes truly circular by expanding the scope of sustainability from process optimization to the entire lifecycle of chemical products."[14] The proposed principles are essentially in link with green chemistry and several notions are related to circular economy approach. However, authors focused their argument in the goal to "make the chemistry circular". In my opinion, the debate is not at this level, and we should not say that "chemistry is circular" or that "we have to make the chemistry circular". For me, the concept of circular economy is much broader than chemistry contribution and, as it will be demonstrated later in this concept article, even if chemists can represent crucial actors of the circular economy, they cannot, by themselves, make the economy circular.

1. Collect and use waste. Waste is a valuable resource that should be transformed into marketable products.

2. Maximize atom circulation. Circular processes should aim to maximize the utility of all atoms in existing molecules.

3. Optimize resource efficiency. Resource conservation should be targeted, promoting reuse and preserving finite feedstock.

4. Strive for energy persistence. Energy efficiency should be maximized. 5. Enhance process efficiency. Innovations should continuously improve in- and post-process reuse and recycling, preferably on-site.

6. No out-of-plant toxicity. Chemical processes should not release any toxic compounds into the environment.

7. Target optimal design. Design should be based on the highest endof-life options, accounting for separation, purification and degradation.

8. Assess sustainability. Environmental assessments should become prevalent to identify inefficiencies in chemical processes.

9. Apply ladder of circularity. The end-of-life options for a product should strive for the highest possibilities on the ladder of circularity.

10. Sell service, not product. Producers should employ service-based business models such as chemical leasing, promoting efficiency over production rate.

11. Reject lock-in. Business and regulatory environment should be flexible to allow the implementation of innovations.

12. Unify industry and provide coherent policy framework. The industry and policy should be unified to create an optimal environment to enable circularity in chemical processes.

Figure 4. The twelve principle of circular chemistry recently proposed by Slootweg et al. ${ }^{[14]}$

In particular, chemists increasingly participate in the valorization of end-of-life products and materials. "Waste" is no longer a dirty word. On the contrary, waste represent new resources and raw material to valorize. ${ }^{[5,15]}$ Interestingly, a Scopus Search based on the scientific publications in the last ten years has shown that an increased number of publications associated "circular economy" and "chemistry" terms, especially from 2016 (Figure 5). In addition, the majority of these articles are about waste valorization, leading this theme as the first studied by chemists in terms of circular economy.

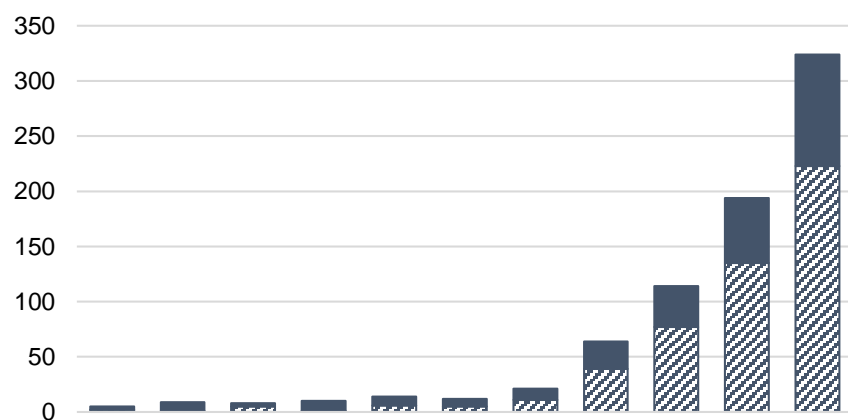

20092010201120122013201420152016201720182019

Figure 5. Number of scientific publications from 2009 to 2019 associating the "circular economy" and "chemistry" terms. The hatched part is the proportion of publications associating also the term "waste". Scopus Search on April, 2020.

Indeed, a huge amount of animal and plant residue are produced each year from agricultural and food sectors. ${ }^{[15]}$ For 
example, biomass is a resource for several platform molecules: lignin as the only large volume renewable feedstock for aromatics (vanillin, $p$-xylene, etc.) ${ }^{[16,17]}$ cellulose and hemicellulose broken down into their constituent hexose and pentose sugars (5hydromethylfurfural platform, 1,4-diacids, etc.) $;^{[18-20]}$ proteins as a source of amino acids (L-phenylanaline, cyanophycin, etc.); $;^{[15,21]}$ algae for the production of polymers; [22] etc. For example, municipal solid waste is not sufficiently considered as a source of carbon and hydrogen to produce a large range of chemicals from methane to alcohols (such as methanol or ethanol) or urea, although a significant research is carried out in the field and an increasing number of gasification plants are now implemented. ${ }^{[23]}$

In Chemistry A European Journal, Centi et al. proposed to develop waste bio-refinery systems, currently mainly focused on waste from agro-food industry, from municipal solid waste limiting additional costs and environmental impact, related to biomass growing, collection and harvesting. ${ }^{[23]}$ Authors wanted to stimulate the development for a large-scale implementation of waste-tochemical technology, in particular to measure their technoeconomic and environmental impacts. They also highlighted the production of syngas from these kind of waste. Syngas is an important intermediate resource for the production of hydrogen, ammonia, methanol, ethanol and synthetic hydrocarbons, used from fuels to chemicals and fertilizers applications.

Lin et al. discussed the example of the circular plastics economy, especially through the food waste biorefinery approach. ${ }^{[10]}$ For example, one important platform molecule obtained from food waste is fructose, a precursor monosaccharide for the production of hydroxymethylfurfural (HMF) which is also a precursor for the synthesis of widely used polyesters such as polyethylene terephthalate (PET) and polyethylene 2,5-furandicarboxylate (PEF), used in plastic bottles manufacturing. Thus, inexpensive and renewable sugars from waste can serve the production of high-value added polyesters.

Agricultural and municipal waste can also be valorized in energy and biofuel, even if the added value (economic, sometimes environmental) is lower than a recovery in molecules of interest. ${ }^{[24,25]}$

At last, innovations of chemists and recent progresses about processes in synthesis of fine chemicals, pharmaceuticals and polymers can also lead to additional contributions of chemistry to the circular economy. ${ }^{[3 a, 10]}$ Advances in catalysis and nanocatalysis, ${ }^{[26]}$ development of applications in greener reaction media (water, supercritical fluids, deep-eutectic solvents, Polyethylene glycol, etc) ${ }^{[27]}$ or in combination with alternate energy input systems (such as microwave, photochemical, mechanochemical or sonochemical or sonophotocatalytical activations) ${ }^{[28]}$ are and will be at the origin of new contributions to circular economy, through their eco-compatible approaches, but also through the innovation that they could bring. For example, we developed at lab a sonochemical process to valorize invasive plants such as Japanese knotweed whose waste obtained after maintenance campaigns (cutting, grubbing-up, etc.) are not accepted in municipal waste. ${ }^{[29]}$ This research work has led to the creation of a start-up to take care of this problem, with a local approach. Power ultrasound, in addition to efficiently contribute to green chemistry, provide favorable energy conditions and physicochemical environment to treat recalcitrant, multicomponent and heterogeneous lignocellulosic biomass, that could be difficult with other classical engineering methods. Ultrasonic energy can meet these challenges. ${ }^{[30]}$

In summary, we have not to expect for the chemistry to be "circular", because these principles are already essentially described in the concept of green chemistry: better use of resources, decrease environmental impacts, prevention of waste formation, etc. This constitutes the level 1 of the contribution of chemistry to the circular economy (Figure 6). However, chemistry has a crucial role to play in this context. A level 2 is to go further in product design: simplify and adapt their syntheses and limit the complexity of these products with the aim of circular economy. Here, chemists have to think how to close loops of production chains and optimize resource efficiency. ${ }^{[5]}$ Innovations, new technologies and new ways of valorization constitute the level 3 based on future ideas of chemists, based on Research and innovative approaches. It is also important to think more globally around a new product or a new process: a global assessment of the concerned sectors is crucial.

\section{New sectors to be properly assessed}

In 2019, Ellen MacArthur Foundation's CE100 network promoted a generalization of the mass balance approach, where all chemicals can be recycled in the same or another product, after being reduced to simpler building blocks to be used as virgingrade feedstock. ${ }^{[31]}$ In the mass balance approach, fossil resources are replaced by sustainable biomass already at the beginning of the production process. The applied share of renewable resources is then allocated to the new product.

Another interesting concept is the industrial symbiosis where the output of one process is the input of an otherwise unrelated process. It can solve, in a local scale system, the problems of eliminating waste and primary resource demand. ${ }^{[32]}$ The examples of industrial symbiosis also revealed a strong ally for the reduction of carbon dioxide emissions and the amount of waste sent to landfills and incinerators.

In these two cited approaches, several notions appear. The first one is about the balance of flows and materials, incoming and outgoing of a synthesis, of a process and on a larger scale, of the company. To better manage the reuse of chemicals and waste, internally or in symbiosis with other industries, it is essential to control this balance, in terms of quantity but also of quality (purity, grade). In this framework, a second notion of enhanced level of transparency is required through the use/establishment of voluntary label certification or traceability models are necessary. ${ }^{[31]}$

From the analysis of 584 published articles, Godina et al. showed that, in Europe and Asia, notably China, where there was a higher prevalence of industrial symbiosis, these approaches are encouraged by the implementation of public policies. ${ }^{[32 a]}$ This review also highlighted that the methods used to quantify the impacts and to analyze the network of industrial symbiosis were essentially focused on the analysis of the specific case studies. ${ }^{[32 a]}$ The methods used to quantify the impacts of industrial symbiosis are very diverse, but the life cycle assessment (LCA) is the most used in these assessments. These analyses are mainly dominated by an environmental approach, followed by the economic aspect. The LCA is based on a comparison between the studied scenario (here, mass balance approach or industrial symbiosis) and reference scenarios (benchmark for the environmental performance of studied scenario). Through the analysis of 26 peer-reviewed papers focused on LCA of industrial symbioses, Aissani et al. revealed a problem of variability of the reference scenario. [33] Indeed, very few authors defined a reference scenario using local aspects, constraints, and needs as product outlets, regulation issues, and stakeholder wishes, while local influence is crucial in industrial symbioses systems.

Contrary to environmental and economic indicators, social indicators are more complex and subjective, and associated data are more difficult to collect. Sutherland et al. proposed several social sustainability indicators, providing operational definitions with quantitative associated measures. ${ }^{[34]}$ Indicator categories related to employees for example can concern their basic needs (e. g. percentage below the poverty line, eligibility for government assistance, etc.), safety/security needs (e. g. health care costs provided by the company, etc.), affiliation needs (e. g. annual retention rate, etc.), esteem needs (e. g. employees believing their contribution to the company is valued, etc.), etc. Thus, the 
social impact remains a point of vigilance to be considered in the development of these new approaches.

LCA is not often applied to laboratory scale, it could be used in order to evaluate a chemical reaction from an environmental point of view. ${ }^{[35]}$ Indeed, LCA takes into account all the life cycle stages of the process and discusses the impact of the environmental burdens inventoried according to a diversity of impact categories.

In addition to the classical and more recently developed green metrics evaluating the sustainability of a reaction or a process, ${ }^{[36]}$ the lab-scale LCA has been developed on several examples, as an advisory tool for sustainable development and circular economy, providing identification of environmental hotspots that stand out. ${ }^{[3]}$ Some researches provide practical framework and expansion to more complex processes in order to show and improve the sustainability of new chemistries and materials. ${ }^{[38]}$ These approaches allow to perform an industrial scale LCA of a production process developed at lab scale, supporting the interest for a scale-up.

The consideration of LCA from the lab scale is therefore an interesting avenue for improving the contribution and impact of chemistry in a context of circular economy (level 4). As this is not a very popular practice among chemists' community, we can recommend the development of expertise in LCA for chemistry, in particular through the implementation of simplified guide and methodologies, but also by teaching it from the university training.

In the case of waste valorization mentioned above, the overall impact of the new valorization streams to implement has to be widely considered upstream, with a multi-impact approach, from an economic, environmental and societal perspective. Indeed, the transition to a stronger circular economy scenario can improve current economic, environmental and social issues such as the development of a new local economy, the creation of new green jobs, the limitation of polluting practices, etc. ${ }^{[13,39]}$ Thus, European Commission estimates that circular economy will have net positive benefits, increasing the EU's GDP by an additional $+0.5 \%$ by 2030 and creating around 700,000 new jobs. ${ }^{[1]}$

However, the development of new value chains in the framework of the circular economy has to pay attention to not destabilize the entire existing value chain and take into account all the collateral (negative) impacts. ${ }^{[40]}$ The situation on a territory can be complex, and that is why it is also crucial to identify all the direct and indirect impacts at the economic, societal and environmental levels, before implementing these changes. For example, the recovery of waste can locally create new competition from businesses or even cause the closure of other existing industries leading to the destruction of jobs despite the creation of new activities in the context of the circular economy. Thus, all these aspects have to be anticipated and prepared, but here, the chemist has a very limited role in responding to these challenges.

\section{New opportunities to be collectively seized}

The consideration of global systems and the evaluation of environmental, social/societal and economic impacts require a multi- and interdisciplinary approach. Indeed, the circular economy involves all the disciplines of Science. Chemistry constitutes one of the links of the chain. Chemists have to work, more and more, with their colleagues in the social sciences and humanities, for example. Interestingly, Martin et al. debated about the interdisciplinary research, at a global level, showing that interdisciplinary research is much touted, but there is confusion about what it means. ${ }^{[41]}$ The success of interdisciplinary research projects ultimately depends on implementation of the concepts. Here, it is indicated that the "good" interdisciplinary research may not have been invented yet, but the circular economy can also be a good pretext for building new operating models between scientific disciplines. In any case, this is what should be encouraged.

The circular economy also requires the participation of not only researchers, but also all the involved actors in the value chain, from the policy makers to businesses and consumers. ${ }^{[10,42]}$ To reach the objectives of the circular economy, all the actors should work together, associated in a consortium for each project, often associated to a delimitated territory.

Based on these latest thoughts, chemists should integrate project of circular economy with a local and global vision, and a multi-partner and multidisciplinary approach. This constitutes the level $\mathbf{5}$ of contribution of chemistry in an economy more circular (Figure 6).

For the example of waste valorization, when waste streams are identified, the collection and the transport issues have to be developed with specific partners on a territory. Due to the limitations of collection systems and mechanical recycling, the recycling rates of major chemical and plastic products are very low (e.g., $9 \%$ worldwide for plastics). ${ }^{[31]}$ There is thus an urgent need to find ways to loop them back into the production systems and move towards a resource efficient circular model. About transport, it is nonsensical to transport large volumes of low value biomass across long distances, although the fact that this is common practice demonstrates it is economical. ${ }^{[3 a]}$ Indeed, transportation of the raw material is not often a major contributor to overall life cycle impacts. For these reasons, local projects of circular economy are recommended, even if a territory could represent a model to then reproduce in other territories.

To improve the quality of the collection, transport and properly reuse of waste, a robust chain of custody approach has to be designed to trace, in total transparency, the flow of materials through a complex value chain. ${ }^{[31]}$ Properties such as origin, production practices and raw material composition should be specified et preserved at each step. For credibility, all chain of custody models need standardization and preferably an independent third-party certification scheme. To this end, allocation rules need to be defined and a certification process set up, including what types of claims can be made and what branding can be used (certifications, labels, standards, etc).

Interestingly, circular economy projects could also bring solutions to more global issues. In the already cited example from our lab, ${ }^{[29]}$ the valorization Japanese knotweed rhizomes leads to the development of new grubbing-up sites as a lever in the fight against the proliferation of this invasive plant, with the aim of preserving biodiversity. Another example discussed by Centi et $a l$. is the use of recovery and alternative raw materials that can represent a challenge in terms of (i) reduction of the greenhouse gas emissions to mitigate climate change, (ii) support to the rural development (iii) anticipate geopolitical issues (security and diversification of resources), (iv) need to find alternative Csources, less depending on the current large fluctuations and uncertainty in future costs of fossil raw materials. ${ }^{[23]}$

European Commission also suggests the development of circular economy to reduce pressure on natural resources, stop the biodiversity loss and reach the climate-neutrality targeted by

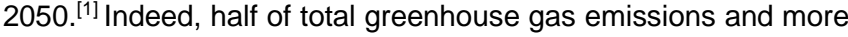
than $90 \%$ of biodiversity loss and water stress come from resource extraction and processing.

The interesting point is how to start this circular economy on a territory. For the valorization of waste for example, if the collection does not exist, it is not possible to valorize, but without an existing valorization, a collection has no reason to exist. This is why the starting point is often an opportunity, a meeting of actors, a multidisciplinary approach, people who want to work together, and who will be able to bring all the actors with them. It is therefore crucial to provoke these opportunities, these meetings, these consortia of actors, these new loops.

For example, in a new context of the Savoie territory (France) where the state services had prohibited open burning of agricultural waste in December 2017 (here, the opportunity), we 
started to work with professionals, elected representatives, cities, state and environmental services, citizens, associations and other researchers (here, the creation of the consortium) in order to find alternatives to the burning of wine waste annually produced in the territory (here, a circular economy to develop). It took over one year to develop the overall consortium and convince all the actors to join us to work together on this local project for the wine sector. We also started to find funding solutions together to start the research (VITIVALO project). ${ }^{[43]}$ Since then, we developed a cascade of valorizations necessary to set up a viable economic sector on the territory, starting with a first step of extraction of molecules of interest. ${ }^{[44]}$ In our case, a single valorization path was not viable at the economic and environmental levels. Thus, we demonstrated that grapecanes and grapevine stocks of the most widespread grapevine varieties in the Savoie Mont Blanc territory constitute important sources of two stilbenes, transresveratrol (Rsv) and trans- $\varepsilon$-viniferin (Vf). These results were promising in comparison with the well-known high stilbenes levels in Pinot Noir and Gewurztraminer varieties but also highlighted the great variability depending on the applied pre-extraction parameters. ${ }^{[45]}$

In the framework of the VITIVALO project, we are working with several researchers, laboratories and companies on the impact on air quality, the recovery of extraction residues in compost and insulating materials to validate the proposed cascade of valorization leading to a "zero waste" approach, but also on comparative LCA to assess the set-up of this new chain on the territory. In addition, several primary schools were involved in the project and large communications dedicated to citizens were organized on the territory to inform them of the developed approach.

In summary, thanks to these broader approaches engaged in the VITIVALO project, the chemists had been able to understand more widely the issues involved in the global project, learnt a lot and finally innovated more than with a more classical and simple "chemist" approach. Here, the consequences of this kind of circular economy project are more numerous than the part on waste valorization, with the reduction of the impact on air quality, the support to changes in the practices of wine-making professions, the help to decision-making, the creation of a new local sector with potential economic impacts on the territory.

A methodology for creating new loops of circularity (new opportunities) was proposed for the chemical industry, based on the principle that "circulating molecules means reusing existing molecules, in either the form of hydrocarbons contained in biomass or in the form of chemical material contained in endconsumer products". [46] Authors specifically proposed a five molecule-circulating loops based on (i) renewable feedstock (ii) increased reuse of products containing chemical industry outputs, (iii) molecule reuse via mechanical recycling, (iv) modification of molecules and reuse as precursors meaning via chemical recycling and $(\mathrm{v})$ energy recovery and reuse of $\mathrm{CO}_{2}$. According to the proposed report, these five loops could lead to the recirculation of around $66 \mathrm{Mt}$ of chemicals each year in Europe. ${ }^{[46]}$ The three described scenarios ("continue as-is", "capitalize on opportunity" and "thought to the end") bring a very interesting positioning on future approaches.

Another way of innovation that circular economy can provoke is the functional economy where customers pay for the use of products and not for their possession. ${ }^{[47,48]}$ Rather than selling products and generating waste, difficult to track and separate, a paradigm shift would allow customers to use an object/product. Indeed, this latter will remain the property of the company that operate it, facilitating its traceability and its recyclability. In our lab for example, we are working on the collection and recovery of coffee grounds, in particular using supercritical fluids. ${ }^{[49]}$ We are working with a local company that collects coffee grounds from restaurants of the territory. We have noticed that the majority of these restaurants are supplied with coffee by the same company.
We could imagine an original system where the latter company, instead of selling coffee, could sell the "coffee service". After its use in the restaurant, the company could recover the coffee grounds to facilitate its recycling or reuse, keeping a complete traceability of the product. More than restaurant waste, it would be a valuable by-product of the company that proposes coffee. An idea to explore in the framework of circular economy...

At last, the multiplication of this type of projects or local initiatives, involving all the actors in the chain, in particular chemists, will also depend on public policy with incentive actions and associated governmental regulations. ${ }^{[50,51]}$ Ranta et al. identified for example that the general drivers of the circular economy from institutional environment of China, United States and Europe support recycling as the primary circular economy action, while support for other types of actions appears to be lacking. Regulatory measures have primarily driven increased recycling efforts on both the integrator and manufacturer sides. Between regions, China differed due to its informal sector and strong regulative institutional support. Authors suggested to improve institutional support for the circular economy and allow it to fulfill its potential as a sustainable growth model. ${ }^{[52]}$

\section{Conclusion: chemists, take your part in the circular economy!}

The circular economy represents a real opportunity of sustainability for our current economical, societal and environmental system, but also of innovation for academic and industrial Research. Chemists of all fields have to work together on it. The solutions are often a combination of expertise and a cascade of approaches, involving organic, inorganic, analytical or polymer chemistries. The solutions will be always collective and complementary!

In this framework, it has been suggested five levels of contribution of chemistry to circular economy (Figure 6):

- level 1: green chemistry and eco-compatible synthesis/processes to limit the negative environmental impact of chemistry;

- level 2: simplification of syntheses and limitation the complexity of the products with closed loops of production chains and optimized resource efficiency;

level 3: innovations, new technologies, new ways of valorization and new concepts;

- level 4: systematic and more generalized environmental/economic assessment, in particular using labscale LCA;

- level 5: consideration of issues/opportunities with a local and global vision, and a multi-partner and multidisciplinary approach.

\section{Contribution of Chemistry to Circular Economy}

Level 5

Multi-partner \& multidisciplinary approach

Level 4 Lab-scale environmental \& economic assessment

Level 3 Innovations, new technologies \& new concepts

Level 2 Simplification \& optimized resource efficiency

Level 1 Green chemistry \& eco-compatible syntheses

Figure 6. Proposed level scale of contribution of chemistry to circular economy 
Chemistry can contribute in each of these levels, but the higher the level, the more the associated projects will have a chance of success with positive impacts, from an economic, societal and environmental point of view. Thus, chemists have to take their part, as an essential link in the chain of actors, in the development of a more circular economy.

This concept article is written in the framework of the third Young Chemists Special Issue 2020 of the journal. Young chemists have the chance to benefit from all the work of our predecessors and more experienced researchers, now available in the literature of recent decades. Young chemists can also sometimes have new visions of approaching issues and concepts. Let's mix all these forms of expertise and work together, all generations combined!

Chemists are not alone in this adventure. They have also to work more closely with other disciplines (economists, sociologists, ecologists, political scientists, computer scientists, etc.) which do not have the same approaches, or the same vocabulary sometimes. However, this multidisciplinarity can lead to such synergistic effects and completely different and innovative approaches!

Some examples given in this paper have shown that a more local approach can respond to local issues that can serve as a demonstrator. In addition to making sense in terms of limiting the transport of materials, creating dedicated jobs and implementing a new local economy, these initiatives can then be replicated in other territories to finally keep a global impact.

To conclude, the circular economy will continue to boost the Research developed by chemists, so let's innovate again!

\section{Acknowledgements}

The author gratefully acknowledges all the students and collaborators that contribute to this exciting research during the last years, in particular: $\mathrm{M}$ Zwingelstein, $\mathrm{A}$. Vandeponseele, V. Quinty, K. Lannuzel, G. Mattioni, M. Bienvenu, A. Belloir, O. Calen A. Lostier, L. Borrel, Dr. M. Chevallier, Dr. F. Le Guern, Dr. R. Duwald, P. Fanget, Dr. C. Piot, Prof. J.-L. Besombes and Prof. M. Draye. He also thanks the Université Savoie Mont Blanc and its foundation, the Auvergne-Rhône-Alpes Region (Pack Ambition Recherche program), the Conseil Savoie Mont Blanc (CSMB), the ADEME Agency, the SATT Linksium Grenoble Alpes (maturation program), the French National Research Agency (ANR, Young Researcher program), as well as TRIALP and EquoVivo companies for their financial supports. GC also thanks all the partners with whom he had the chance to collaborate, at local, national and international levels, whether scientists, local authorities, actors of the society, associations, companies, elected officials and all the professionals for their actions and their enthusiasm in the joint development of projects. Thank you also to the Societé Chimique de France (SCF and its RJ-SCF) and the European Chemical Society (EuChems and its EYCN) for their support for young chemists.

Keywords: sustainability - green chemistry - life cycle assessment $\bullet$ valorization $\bullet$ waste

[1] European Commission, Press release, March $11^{\text {th }}, 2020$, online: https://ec.europa.eu/commission/presscorner/detail/en/IP $20 \quad 420$ (Accessed 10 May 2020)

[2] V. Rizos, K. Tuokko, A. Behrens, CEPS Res. Report. 2017, 8, 41 p.

[3] (a) J. H. Clark, T. J. Farmer, L. Herrero-Davila, J. Sherwood, Green Chem. 2016, 18, 3914- 3934; (b) W. R. Stahel, Nature 2016, 531, 435438.
[4] (a) P. T. Anastas, J. C. Warner, Green Chemistry: Theory and Practice, Oxford University Press, Oxford,1998; (b) P. T. Anastas, T. C. Willamson, ACS Symp. Series, 1996, 626, 1-17; (c) P. Anastas, N. Eghbali, Chem. Soc. Rev. 2010, 39, 301-312.

[5] R. A. Sheldon, Green Chem. 2016, 18, 3180-3183.

[6] (a) B. M. Trost, Science, 1991, 254, 1471-1477; (b) R. A. Sheldon, Chem. Ind. 1992, 903-906; (c) R. A. Sheldon, Green Chem. 2017, 19 18-43.

[7] (a) P. T. Anastas, M. M. Kirchhoff, T. C. Willamson, Appl. Catal. A Gen. 2001, 1-2, 3-13; (b) R. A. Sheldon, Chem. Commun. 2008, 29, 3352-3365.

[8] (a) C. H. Christensen, J. Rass-Hansen, C. C. Marsden, E. Taarning, K. Egeblad, ChemSusChem 2008, 4, 283-289; (b) J. H. Clark, V. Budarin, F. E. I. Deswarte, J. J. E. Hardy, F. M. Kerton, A. J. Hunt, R. Luque, D. J. Macquarrie, K. Milkowski, A. Rodriguez, $O$ Samuel, S. J. Tavener, R. J. White, A. J. Wilson, Green Chem. 2006 8, 853-860.

[9] (a) P. T. Anastas, J. B. Zimmerman, Environ. Sci. Tech. 2003, 5, 95A-101A; (b) S. Y. Tan, R. A. Bourne, R. L. Smith, M. Poliakoff, Green Chem. 2008, 10, 268-269.

[10] G. Kaur, K. Uisan, K. L. Ong, C. S. K. Lin, Curr. Opinion Green Sustain. Chem. 2018, 9, 30-39.

[11] G. H. Brundtland, United Nations Report, Our common future, March 1987.

[12] J. H. Clark, T. J. Farmer, L. Herrero-Davila, J. Sherwood, Green Chem. 2016, 18, 3914-3934.

[13] K. Kümmerer, J. H. Clark, V. G. Zuin, Science 2020, 6476, 369370.

[14] T. Keijer, V. Bakker, J. C. Slootweg, Nature Chem. 2019, 11, 190195.

[15] C. O. Tuck, E. Pérez, I. T. Horváth, R. A. Sheldon, M. Poliakoff, Science, 2012, 337, 695-699.

[16] M. Graglia, N. Kanna, D. Esposito, ChemBioEng Rev. 2015, 6 , 377-392.

[17] R. Behling, S. Valange, G. Chatel, Green Chem. 2016, 18, 18391854.

[18] J. Artz, R. Palkovits, Curr. Opin. Green Sustain. Chem. 2018, 14, 14-18.

[19] F. H. Isikgor, C. R. Becer, Polym. Chem. 2015, 6, 4497-4559.

[20] S. Takkellapati, T. Li, M. A. Gonzales, Clean Technol. Environ. Pol. 2018, 20, 1615-1630.

[21] Y. Gong, H. Hu, Y. Gao, X. Xu, H. Gao, J. Industr. Microbiol. Biotechn. 2011, 38, 1879-1890

[22] A. Noreen, K. M. Zia, M. Zuber, M. Ali, M. Mujahi, Int. J. Biol. Macromol. 2016, 86, 937-949.

[23] G. Iaquaniello, G. Centi, A. Salladini, E. Palo, S. Perathoner, Chem. Eur. J. 2018, 46, 11831-11839.

[24] T. A. Trabold, D. R. Alberto, In: Sustainability of the Food System: Sovereignty, Waste, and Nutrients Bioavailability, Elsevier (Edt. N. Betoret, E. Beteret): 2020, chapter 4, 53-69.

[25] F. J. Ortiz, A. Kruse, F. Ramos, P. Ollero, Energ. Convers. Manage. 2019, 180, 1167-1184.

[26] (a) Z. Guo, B. Liu, Q. Zhang, W. Deng, Y. Wang, Y. Yang, Chem Soc. Rev. 2014, 43, 3480-3524; (b) V. Calvino-Casilda, A. J. LópezPeinado, R. M. Martín-Aranda, E. Pérez Mayoral, Nanocatalysis: Applications and Technologies, CRC Press: Boca Raton, USA, 2019, 304 p.; (c) S. Wacławek, V.V.T. Padil, M. Černík, Ecol. Chem. Eng. S. 2018, 1, 9-34.

[27] (a) L. S. Torres-Valenzuela, A. Ballesteros-Gómez, S. Rubio, Food Engin. Rev. 2020, 12, 83-100; (b) L. Soh, M. J. Eckelman, ACS Sustainable Chem. Eng. 2016, 11, 5821-5837; (c) C. J. Clarke, W.Ch. Tu, O. Levers, A. Bröhl, J. P. Hallett, Chem. Rev. 2018, 2, 747800.

[28] (a) S. Tabasso, D. Carnaroglio, E. Calcio Gaudino, G. Cravotto, Green Chem. 2015, 17, 684-693; (b) F. Jérôme, G. Chatel, K. De Oliveira Vigier, Green Chem. 2016, 18, 3903-3913; (c) E. Kuna, R. Behling, S. Valange, G. Chatel, J. C. Colmenares, Top. Curr. Chem. 2017, 375, 41; (d) V. Nair, M. J. Munoz-Batista, M. Fernandez-Garcia R. Luque, J. C. Colmenares, ChemSusChem 2019, 12, 2098-2116. [29] (a) G. Chatel, M. Draye, F. Le Guern, C. Piot, E-Soleau DSO2018014351, 2018; (b) G. Chatel, R. Duwald, M. Draye, P. Fanget, C. Piot, E-Soleau, DSO2020006841, 2020; (c) G. Chatel, R Duwald, M. Draye, P. Fanget, C. Piot, Patent, FR $2006171,2020$. 
[30] (a) G. Chatel, Ultrason. Sonochem. 2018, 40, 117-122; (b) G. Chatel, K. De Oliveira Vigier, F. Jérôme, ChemSusChem, 2014, 10, 2774-2787.

[31] Ellen MacArthur Foundation's CE100 network, Enabling a circulair economy for chemicals with the mass balance approach, white paper published on https://www.ellenmacarthurfoundation.org/, May 2019, 35 p.

[32] (a) A. Neves, R. Godina, S. G. Azevedo, J. C. O. Matias, J. Clean. Prod. 2020, 247, 119113; (b) Z. Yeo, D. Masi, J. S. Choong Low, Y Ting Ng, P. Siew Tan, S. Barnes, J. Indus. Ecol. 2019, 23, 1087-1108. [33] L. Aissani, A. Lacassagne, J.-B. Bahers, S. Le Féon, J. Indus. Ecol. 2019, 23, 972-985.

[34] M. J. Hutchins, J. S. Richter, M. L. Henry, J. W. Sutherland, J. Clean. Prod. 2019, 212, 687-697.

[35] (a) X. Domènech, J. A. Ayllon, J. Peral, Environ. Sci. Technol. 2002, 36, 5517-5520; (b) M. Pini, R. Rosa, P. Neri, A. M. Ferrari, (2020) LCA Application to Chemical Synthesis at Laboratory Scale. In: Life Cycle Assessment in the Chemical Product Chain, Eds: S. Maranghi, C. Brondi, Springer Nature Switzeland: 2020, p. 101-123.

[36] (a) D. J. C. Constable, A. D. Curzons, V. L. Cunningham, Green Chem. 2002, 4, 521-527; (b) D. J. Constable, C. Jiménez-Gonzalez, Green Metrics, In: Handbook of Green Chemistry, Wiley-VCH: 2018, Vol. 11, Weinheim, Germany, 299 p.

[37] (a) G. Pallas, M. G. Vijver, W. J. G. M. Peijnenburg, J. Guinée, J. Indus. Ecol. 2020, 24, 193-204; (b) F. Gallu, C. Pirola, D. Previtali, F. Manentu, C. L. Blanchi, J. Clean. Prod. 2018, 171, 147-152.

[38] F. Piccinno, R. Hischier, S. Seeger, C. Som, J. Clean. Prod. 2016 135, 1085-1097.

[39] (a) P. Schroeder, K. Anggraeni, U. Weber, J. Indus. Ecol. 2018 , 23, 77-95; (b) S. K. Singh, A. P. Singh, Manage. Decis. 2019, 57, 937952; (c) P. Ghisellini, C. Cialani, S. Ulgiati, J. Clean. Prod. 2016, 114, 11-32.

[40] (a) J. Fellner, J. Lederer, C. Scharff, D. Laner, J. Indus. Ecol. 2017, 3, 494-496; (b) J. Korhonen, A. Honkasalo, J. Seppälä, Ecol. Econ. 2018, 143, 37-46.

[41] D. W. Robertson, D. K. Martin, P. A. Singer, BMC Med. Res. Method. 2003, 3, 20.

[42] F. Preston, A Global Redesign? Shaping the Circular Economy? London: Chatham House: The Royal Institute of International Affairs; 2012,

https://www.chathamhouse.org/publications/papers/view/182376

(Accessed 10 May 2020).

[43] VITIVALO Project, http://www.vitivalo.univ-smb.fr (Accessed 10 May 2020).

[44] M. Zwingelstein, M. Draye, J.-L. Besombes, C. Piot, G. Chatel, Waste Manag. 2020, 102, 782-794.

[45] M. Zwingelstein, M. Draye, J.-L. Besombes, C. Piot, G. Chatel, ACS Sustainable Chem. Eng. 2019, 9, 8310-8316.

[46] Accenture, Taking the European Chemical Industry into the circular economy, https://www.accenture.com/us-en/insight-circulareconomy-european-chemical-industry (Accessed 10 May 2020).

[47] A. Urbinati, D. Chiaroni, V. Chiesa, J. Clean. Prod. 2017, 168, 487-498.

[46] A. Tukker, J. Clean. Prod. 2015, 97, 76-91.

[48] A. Vandeponseele, M. Draye, C. Piot, G. Chatel, Green Chem. 2020, submitted.

[49] L. Millios, Sustain. Sci. 2018, 13, 861-878.

[50] J. Kirchherr, L. Piscicelli, R. Bour, E. Kostense-Smit, J. Muller, A. Huibrechtse-Truijens, M. Hekkert, Ecol. Econ. 2018, 150, 264-272.

[51] V. Ranta, L. Aarikka-Stenroos, P. Ritala, S. J. Mäkinen, S. J. Resources, Conserv. Recycling 2018, 135, 70-82. 


\section{Entry for the Table of Contents}
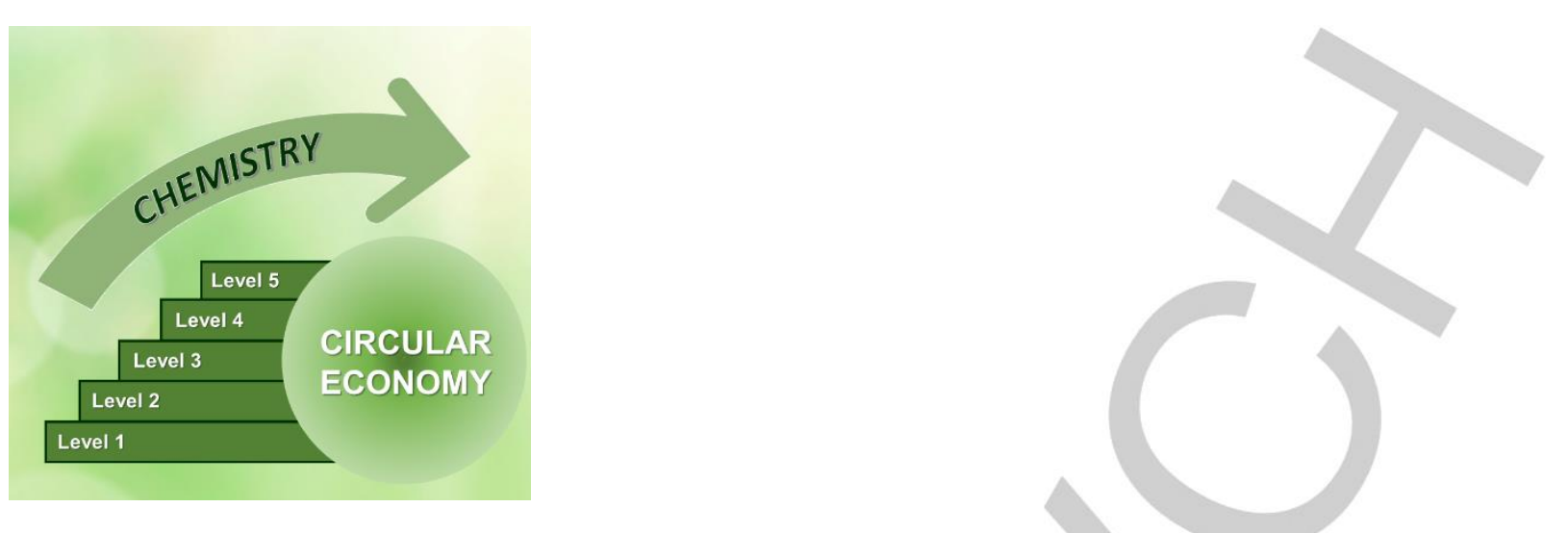

Chemists are not alone in the adventure of circular economy. Innovative approaches are necessary through the development of multidisciplinary, multi-partners and local projects. This concept article, written in the framework of the third Young Chemists Special Issue, proposed five levels of contribution of chemistry to circular economy to develop new opportunities of sustainability and ensure a better economical, societal and environmental approach in this kind of projects.

Institute and researcher Twitter usernames: @Univ Savoie ; @gregory chatel 